\title{
Tryptophan-Niacin Metabolism in Alloxan Diabetic Rats and Partial Prevention of Alloxan Diabetes by Nicotinamide
}

\author{
Katsumi SHIBATA \\ Laboratory of Nutritional Biochemistry, Department of Food Science \\ and Nutrition, Faculty of Domestic Science, Teikoku Women's \\ University, Moriguchi, Osaka 570, Japan
}

Received September 1, 1986

\begin{abstract}
After male rats of the Sprague Dawley strain, 5 weeks old, were fed a $20 \%$ casein diet with or without $0.5 \%$ nicotinamide for 13 days, $180 \mathrm{mg} / \mathrm{kg}$ body weight of alloxan was injected intraperitoneally into the rats. The rats were kept for 18 days with the same diet. The level of blood glucose was increased 6-fold in the group on a $20 \%$ casein diet by the injection of alloxan, while there was only a 2 -fold increase in the group on a nicotinamide-containing diet and the decreased body weight was also lower in the group on the nicotinamide diet than the group on the casein diet. The body weight was indirectly related to the concentration of blood glucose. A marked increase was observed in the activities of tryptophan oxygenase, aminocarboxymuconate-semialdehyde decarboxylase, and nicotinamide methyltransferase upon the injection of alloxan with both diets; on the other hand, the activities of kynureninase and $\mathrm{NAD}^{+}$synthetase were decreased by the injection of alloxan. The activity of kynurenine aminotransferase increased in the group on the $20 \%$ casein diet by the injection of alloxan, while in the group on the nicotinamide-containing diet its activity was not increased by the injection. These changes in the above enzyme activities mean that the conversion ratio from tryptophan to niacin is lower in the alloxan diabetic rat than normal rat. It was found that the activities of tryptophan oxygenase, aminocarboxymuconate-semialdehyde decarboxylase, and nicotinamide methyltransferase were directly related to the concentration of blood glucose, and that the activities of kynureninase and NAD ${ }^{+}$synthetase were inversely related. There was no difference in the activities of 3-hydroxyanthranilic acid oxygenase and nicotinamide mononucleotide adenylyltransferase upon the injection of alloxan with both diets.
\end{abstract}

Mehler et al. ${ }^{1)}$ showed that the level of liver aminocarboxymuconate-semialdehyde decarboxylase increased greatly in alloxan-diabetic rats and was inversely related to urinary excretion of $N^{1}$-methylnicotinamide (MNA). Later, Ikeda et al. ${ }^{2)}$ and Sanada et al. ${ }^{3)}$ confirmed these results. Kotake and $\mathrm{Tani}^{4)}$ and Rosen et al. ${ }^{5)}$ reported the increased urinary xanthurenic acid in diabetic patients. It is evident that in the alloxan diabetic rat there is some disturbance in the metabolism of tryptophan-niacin. Therefore, I investigated precisely the effects of alloxan administration on the metabolism of tryptophan-niacin in rats fed a $20 \%$ casein diet with or without large amounts of nicotinamide. This paper reports that many of the enzyme activities involved in the metabolism of tryptophan-niacin change depending on the level of blood glucose.

\section{MATERIALS AND METHODS}

Chemicals. Vitamin-free milk casein, sucrose, cholinechloride, phenazine methosulfate, nicotinamide, tryptophan, and "Glucose-Test wako $_{\text {" were purchased from }}$ Wako Pure Chemical Industries Ltd. Kynurenine sulfate, 3-hydroxyanthranilic acid, and 3-(4,5-dimethyl-2thiazolyl)-2,5-diphenyl- $2 \mathrm{H}$-tetrazolium bromide were from Tokyo Kasei Kogyo Co., Ltd. The Harper's salt mixture, the Oriental's vitamin mixture, ATP, and $\mathrm{NAD}^{+}$, were obtained from the Oriental Yeast Co., Ltd. Nicotinamide mononucleotide (NMN), nicotinic acid adenine dinucleotide, MNA, and $S$-adenosylmethionine were obtained from the Sigma Chemical Company. Other chemicals were of the highest purity available from commercial sources.

Animal and diets. Male rats of the Sprague Dawley strain, 5 weeks old were obtained from Clea Japan Inc. 
The rats, kept in individual wire-bottomed cages, were fed a $20 \%$ casein diet with or without $0.5 \%$ nicotinamide $(20 \%$ casein diet: $20 \%$ casein, $0.2 \%$ L-methionine, $68.8 \%$ sucrose, $5 \%$ corn oil, $5 \%$ Harper's salt mixture, $1 \%$ Oriental's vitamin mixture; nicotinamide containing diet: $100 \mathrm{~g}$ of the $20 \%$ casein diet $+0.5 \mathrm{~g}$ of nicotinamide). At the 13 th day of the experiment, $180 \mathrm{mg} / \mathrm{kg}$ body weight of alloxan dissolved in $0.5 \mathrm{ml}$ of sterilized $0.9 \% \mathrm{NaCl}$, was injected intraperitoneally into the rats. As the control, saline was injected. These rats were kept for 18 more days and then killed at 9:00 10:00. Food and water were supplied $a d$ libitum. The room temperature was $22 \pm 2^{\circ} \mathrm{C}$ and humidity about $60 \%$. The light-darkness cycle was $06: 00 \sim 18: 00$ (light) and 18:00 06:00 (darkness). Food intake and body weight were measured at around 10:00.

Enzyme assay and measurement of blood glucose. The liver was removed from the rat under sodium pentobarbital anesthesia, washed with cold $0.9 \% \mathrm{NaCl}$, and blotted with paper. The preparation of the enzyme source and the methods for measuring NMN adenylyltransferase (NMN ATase, EC 2.7.7.1), NAD ${ }^{+}$synthetase (NAD Sase, EC 6.3.5.1), and nicotinamide methyltransferase (NMTase, EC 2.1.1.1) were described in a previous paper. ${ }^{6)}$

The activity of tryptophan oxygenase (TOase, EC 1.13.11.11) was measured by a modification of the method of Knox et al. ${ }^{7)}$ as follows. The reaction mixture $(2.5 \mathrm{ml})$ comprised $0.3 \mathrm{ml}$ of $0.5 \mathrm{M}$ potassium phosphate buffer, $\mathrm{pH}$ $7.0,0.2 \mathrm{ml}$ of $50 \mathrm{~mm}$ L-tryptophan, $1.85 \mathrm{ml}$ of water, and $0.15 \mathrm{ml}$ of liver homogenate. The mixture was incubated at $37^{\circ} \mathrm{C}$ for $1 \mathrm{hr}$. The reaction was stopped by immersing the reaction tubes in a boiling water bath for $3 \mathrm{~min}$. After being cooled on ice, the mixture was centrifuged and the absorbance at $360 \mathrm{~nm}$ was measured. As the reference, the mixture without L-tryptophan was used.

The activity of kynureninase (Kyase, EC 3.7.1.3) was measured by a modification of the method of Takeuchi $e t$ $a l .^{8)}$ as follows. The reaction mixture $(1 \mathrm{ml})$ comprised $0.2 \mathrm{ml}$ of $0.5 \mathrm{M}$ Tris- $\mathrm{HCl}$ buffer, $\mathrm{pH} 8.0,10 \mu \mathrm{l}$ of $1 \mathrm{~mm}$ pyridoxal phosphate, $0.58 \mathrm{ml}$ of water, and $0.2 \mathrm{ml}$ of liver homogenate. After this mixture was incubated at $37^{\circ} \mathrm{C}$ for $5 \mathrm{~min}, 10 \mu \mathrm{l}$ of $50 \mathrm{~mm} \mathrm{~L}$-kynurenine was added to the mixture and incubated at $37^{\circ} \mathrm{C}$ for $30 \mathrm{~min}$. The reaction was stopped by the addition of $1 \mathrm{ml}$ of $10 \%$ trichloroacetic acid, and then $4 \mathrm{ml}$ of ethylacetate. After this mixture was mixed thoroughly, it was centrifuged. The upper layer (ethylacetate fraction) of the supernatant was removed and its fluorescence intensity was measured at an excitation wavelength of $350 \mathrm{~nm}$ and an emission wavelength of $400 \mathrm{~nm}$. As the reference, the mixture at 0 time incubation was used.

The activity of 3-hydroxyanthranilic acid oxygenase (3OHAnA Oase, EC 1.13.11.6) was measured by a modification of the method of Decker et al. ${ }^{9)}$ as follows. The reaction mixture ( $3 \mathrm{ml}$ in the cuvette) containing $0.1 \mathrm{ml}$ of $3.30 \mathrm{~mm}$ 3-hydroxyanthranilic acid (dissolved in $50 \mathrm{~mm}$ Tris-acetate buffer, $\mathrm{pH} 8.0$ ), $1 \mathrm{ml}$ of $0.2 \mathrm{M}$ Tris-acetate buffer, $\mathrm{pH} 8.0$, and $1.88 \mathrm{ml}$ of water was incubated for $5 \mathrm{~min}$ at $25^{\circ} \mathrm{C}$. The reaction was started by the injection of $20 \mu$ of the supernatant of a liver homogenate (centrifuged at $20,000 \times g$ for $20 \mathrm{~min}$ ) and the rate of the reaction was calculated at $360 \mathrm{~nm}$ from the linear portion of the optical density versus time curve.

The activity of kynurenine aminotransferase (Ky ATase, EC 2.6.1.7) was measured by a modification of the method of Tobes and Mason ${ }^{10)}$ as follows. The reaction mixture $(0.5 \mathrm{ml})$ comprised $0.1 \mathrm{ml}$ of $0.1 \mathrm{M}$ potassium phosphate buffer, $\mathrm{pH} 7.5,0.1 \mathrm{ml}$ of $1 \mathrm{~mm}$ pyridoxal phosphate, $0.1 \mathrm{ml}$ of $30 \mathrm{~mm} \alpha$-ketoglutaric acid, and $0.1 \mathrm{ml}$ of the liver homogenate. This mixture was incubated for $5 \mathrm{~min}$ at $37^{\circ} \mathrm{C}$, and then $0.1 \mathrm{ml}$ of $10 \mathrm{~mm}$ kynurenine was added and incubated for $20 \mathrm{~min}$ at $37^{\circ} \mathrm{C}$. The reaction was stopped by the addition of $5 \mathrm{ml}$ of $1 \%$ borate (dissolved in ethanol). The mixture was centrifuged at $10,000 \times g$ for $10 \mathrm{~min}$. One milliliter of $0.3 \mathrm{M}$ zinc acetate was added to $2 \mathrm{ml}$ of the supernatant and the fluorescence intensity of the mixture was measured at an excitation wavelength of $344 \mathrm{~nm}$ and an emission wavelength of $398 \mathrm{~nm}$. As the reference, the fluorescence intensity of the supernatant in the absence of zinc acetate was measured.

The activity of aminocarboxymuconate-semialdehyde decarboxylase (ACMSDase, EC 4.1.1.45) was measured by a modification of the method of Ichiyama et al. ${ }^{11)}$ as follows. The reaction mixture $(0.5 \mathrm{ml})$ comprised $0.15 \mathrm{ml}$ of $3.3 \mathrm{~mm}$ 3-hydroxyanthranilic acid (dissolved in $50 \mathrm{~mm}$ Tris-acetate buffer, $\mathrm{pH} 8.0$ ), $0.125 \mathrm{ml}$ of $0.2 \mathrm{M}$ Tris-acetate buffer, $\mathrm{pH} 8.0,0.025 \mathrm{ml}$ of water, and $0.1 \mathrm{ml}$ of partially purified 3-hydroxyanthranilic acid oxygenase. This mixture was incubated at $37^{\circ} \mathrm{C}$ for $5 \mathrm{~min}$ and $0.1 \mathrm{ml}$ of the supernatant of the liver homogenate (centrifuged at $20,000 \times g$ for $20 \mathrm{~min}$ ) was added. The reaction was done at $37^{\circ} \mathrm{C}$ for $10 \mathrm{~min}$ and the reaction was stopped by immersion in a boiling water bath for $10 \mathrm{~min}$. The supernatant was obtained by centrifugation at $10,000 \times g$ for $10 \mathrm{~min}$. The precipitated materials were twice extracted with $0.5 \mathrm{ml}$ of water. The combined supernatant was spotted on a Silica Gel plate $60 \mathrm{~F}_{254}$ and developed with $n$ butanol saturated with $3 \%$ ammonia (upper layer). The area of picolinic acid was scraped off and then extracted with $1 \mathrm{ml}$ of water. The extract, filtered through a $0.045 \mu \mathrm{m}$ filter was analyzed by an HPLC system: column, Chemcosorb $7 \mathrm{CH}(4.6 \times 150 \mathrm{~mm}$, Chemco Scientific Co., Ltd., Osaka); flow rate, $1 \mathrm{ml} / \mathrm{min}$; wavelength, $260 \mathrm{~nm}$; mobile phase, $100 \mathrm{~mm} \mathrm{KH}_{2} \mathrm{PO}_{4}(\mathrm{pH} 4.5)$; temperature, $25^{\circ} \mathrm{C}$. Picolinic acid was eluted at $4.9 \mathrm{~min}$.

To measure blood glucose, $20 \mu \mathrm{l}$ of blood taken from the rat's tail vein at 9:00 10:00 was mixed with $0.5 \mathrm{ml}$ of $5 \%$ trichloroacetic acid. The mixture was kept for $5 \mathrm{~min}$ at room temperature and then centrifuged in an Eppendorf centrifuge 5412. The supernatant was analyzed for glucose using "Glucose-Test wako."

Statistical analysis. Significant differences between means having the same variance and different variance as 
analyzed by the F-test were evaluated by Student's $t$-test and the Cochran-Cox test, respectively. ${ }^{19)}$

\section{RESULTS}

Correlation between changes in body weight and the concentration of blood glucose

The levels of blood glucose of all four rats fed the control diet were increased greatly by the injection of alloxan and one rat died on the 12 th day after the injection. On the other hand, of six rats fed the nicotinamide diet, its levels in three rats increased, but not in three other rats. The level of blood glucose was found to be increased by the feeding of the nicotinamide diet compared with the control diet, as shown in Table I. Body weight was decreased by the injection of alloxan, especially the group on the control diet as shown in Table I.

Figure 1 shows a correlation between the changes in body weight and the concentration of blood glucose in the alloxan-injected groups. The body weight gain was indirectly proportional to the level of blood glucose and this relation was significant at $p<0.05$.

The enzyme activities concerned with tryptophan-niacin metabolism in liver

Table II shows the enzyme activities concerned with the tryptophan-niacin metabolism in liver. The activities of tryptophan oxygenase, aminocarboxymuconate-semialdehyde decarboxylase, and nicotinamide methyltransferase were increased by the injection of alloxan, especially in the group on the control diet, while the activity of $\mathrm{NAD}^{+}$synthetase was decreased by the injection of alloxan. The activity of kynureninase was not statistically decreased by the injection of alloxan, but, it was observed that its activity had a tendency to be lower in the group of $\mathrm{C}-\mathrm{A}$ than in the group of $\mathrm{C}-\mathrm{C}$. The activity of kynurenine aminotransferase in the group on the control diet was greatly increased by the injection of alloxan but not in the group on the nicotinamide diet. The activities of 3-hydroxyanthranilic acid oxygenase and NMN adenylyltransferase were not changed by the injection of alloxan in both groups on the control and
Table I. Levels of Blood Glucose and Changes IN Body WeIGHT

\begin{tabular}{ccc}
\hline & $\begin{array}{c}\text { Blood glucose } \\
(\mathrm{mg} / \mathrm{ml} \text { whole blood })\end{array}$ & $\begin{array}{c}\text { Changes in body } \\
\text { weight* } \\
(\mathrm{g})\end{array}$ \\
\hline $\mathrm{C}-\mathrm{C}^{1}$ & $0.86 \pm 0.28^{\mathrm{a}}$ & $80.6 \pm 10.1^{\mathrm{a}}$ \\
$\mathrm{C}-\mathrm{A}^{2}$ & $5.16 \pm 2.33^{\mathrm{a}, \mathrm{c}}$ & $-44.6 \pm 36.1^{\mathrm{b}, \mathrm{c}}$ \\
$\mathrm{N}-\mathrm{C}^{3}$ & $1.65 \pm 0.22^{\mathrm{b}, \mathrm{c}}$ & $69.1 \pm 5.6^{\mathrm{a}, \mathrm{c}}$ \\
$\mathrm{N}-\mathrm{A}^{4}$ & $3.10 \pm 1.64^{\mathrm{b}, \mathrm{c}}$ & $8.6 \pm 14.1^{\mathrm{b}}$ \\
\hline
\end{tabular}

One rat in the $\mathrm{C}-\mathrm{A}$ group died on the 12th day after the injection. Values are mean \pm S.D. for $5,3,4$, and 6 rats in the groups of $\mathrm{C}-\mathrm{C}, \mathrm{C}-\mathrm{A}, \mathrm{N}-\mathrm{C}$, and $\mathrm{N}-\mathrm{A}$, respectively. A different superscript letter in the same column means a statistically significant difference at $p<0.05$.

1 The group of rats fed the control diet and injected with $0.9 \% \mathrm{NaCl}$.

2 The group of rats fed the control diet and injected with alloxan.

3 The group of rats fed the nicotinamide diet and injected with $0.9 \% \mathrm{NaCl}$.

4 The group of rats fed the nicotinamide diet and injected with alloxan.

* These values are changes in body weight after the injection of alloxan. Food intakes in the groups of $\mathrm{C}-\mathrm{C}, \mathrm{C}-\mathrm{A}, \mathrm{N}-\mathrm{C}$, and $\mathrm{N}-\mathrm{A}$ after the injection were $348.0 \pm 39.2, \quad 472.7 \pm 80.5, \quad 330.0 \pm 15.7, \quad$ and $334.5 \pm 95.1 \mathrm{~g}$, respectively.

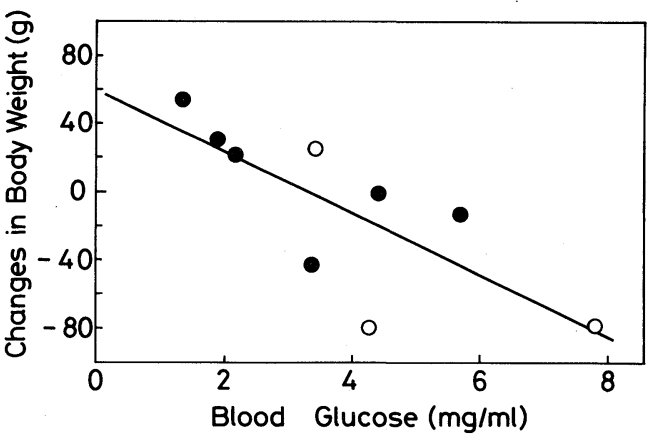

FIG. 1. Correlation between the Concentration of Blood Glucose and the Changes in Body Weight of Rats.

O, C-A; O, N-A. Regression line: body weight $(\mathrm{g})=$ $(-17.94) \times($ Blood Glucose $\quad(\mathrm{mg} / \mathrm{ml}))+(59.1) \quad(r=$ $-0.751, p<0.05)$.

nicotinamide diets.

Correlation between the enzyme activities involved in the pathway of tryptophan-niacin and the concentration of blood glucose in the alloxan-injected groups

Figures $2 \sim 6$ show correlations between the 
Table II. Liver EnZyme Activities Concerned with Tryptophan-NiaCin Metabolism

\begin{tabular}{lcccc}
\hline & C-C & C-A & N-C & N-A \\
\hline TOase & $1.81 \pm 0.16^{\mathrm{a}}$ & $6.05 \pm 3.29^{\mathrm{a}, \mathrm{c}}$ & $2.17 \pm 0.31^{\mathrm{a}, \mathrm{c}}$ & $3.81 \pm 1.72^{\mathrm{b}, \mathrm{c}}$ \\
Kyase & $0.171 \pm 0.048^{\mathrm{a}}$ & $0.116 \pm 0.0312^{\mathrm{a}}$ & $0.169 \pm 0.029^{\mathrm{a}}$ & $0.143 \pm 0.049^{\mathrm{a}}$ \\
3-OHAnA Oase & $536.8 \pm 321^{\mathrm{a}}$ & $718.2 \pm 262.9^{\mathrm{a}}$ & $468.6 \pm 86.0^{\mathrm{a}}$ & $507.2 \pm 72.5^{\mathrm{a}}$ \\
ACMSDase & $29.2 \pm 1.7^{\mathrm{a}}$ & $105.7 \pm 21.9^{\mathrm{b}, \mathrm{d}}$ & $15.1 \pm 4.3^{\mathrm{c}}$ & $61.7 \pm 37.9^{\mathrm{a}, \mathrm{d}}$ \\
NMN ATase & $5.63 \pm 0.62^{\mathrm{a}}$ & $6.18 \pm 0.50^{\mathrm{a}}$ & $5.70 \pm 0.95^{\mathrm{a}}$ & $6.00 \pm 0.64^{\mathrm{a}}$ \\
NAD Sase & $0.826 \pm 0.100^{\mathrm{a}}$ & $0.374 \pm 0.093^{\mathrm{b}, \mathrm{c}}$ & $0.632 \pm 0.188^{\mathrm{a}, \mathrm{c}}$ & $0.430 \pm 0.082^{\mathrm{b}, \mathrm{c}}$ \\
NMTase & $0.31 \pm 0.13^{\mathrm{a}}$ & $1.69 \pm 0.50^{\mathrm{b}}$ & $0.64 \pm 0.20^{\mathrm{c}}$ & $1.74 \pm 0.51^{\mathrm{a}}$ \\
Ky ATase & $11.58 \pm 5.47^{\mathrm{a}}$ & $39.64 \pm 8.56^{\mathrm{b}}$ & $12.60 \pm 4.74^{\mathrm{a}}$ & $12.79 \pm 6.34^{\mathrm{a}}$ \\
\hline
\end{tabular}

Values are expressed as $\mu \mathrm{mol} / \mathrm{hr} / \mathrm{g}$ fresh weight. A different superscript letter in the same enzyme means a statistically significant difference at $p<0.05$. The other explanations are the same as in Table I.

TOase, tryptophan oxygenase; Kyase, kynureninase; 3-OHAnA Oase, 3-hydroxyanthranilic acid oxygenase; ACMSDase, aminocarboxymuconate-semialdehyde decarboxylase; NMN ATase, nicotinamide mononucleotide adenylyltransferase, NAD Sase, NAD $^{+}$synthetase; NMTase, nicotinamide methyltransferase; Ky ATase, kynurenine aminotransferase.

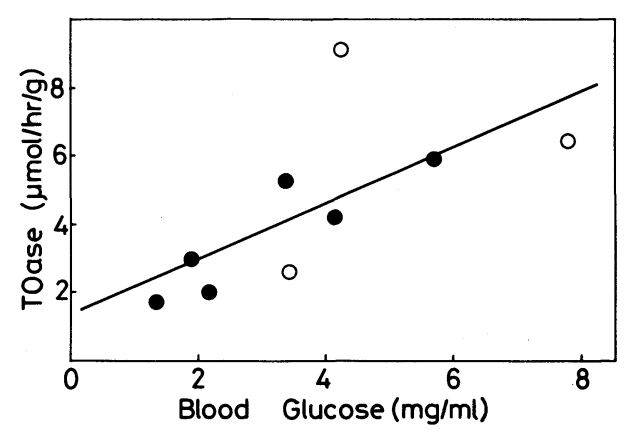

FIG. 2. Correlation between the Concentration of Blood Glucose and the Activity of Tryptophan Oxygenase.

The symbols are the same as in Fig. 1. Regression line: TOase $(\mu \mathrm{mol} / \mathrm{hr} / \mathrm{g})=(0.925) \times($ Blood Glucose $(\mathrm{mg} / \mathrm{ml}))$ $+(0.814)(r=0.675, p<0.05)$.

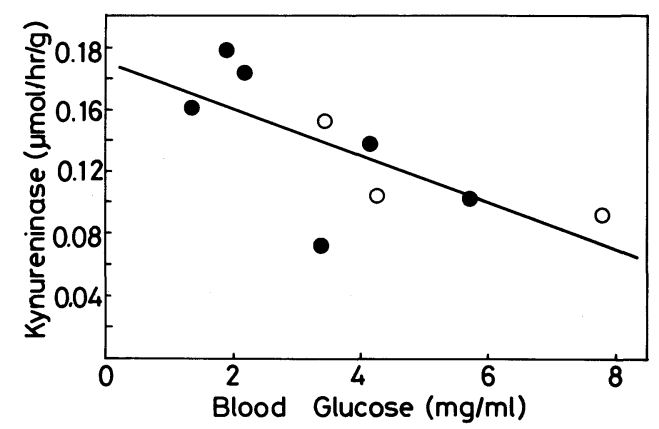

FIG. 3. Correlation between the Concentration of Blood Glucose and the Activity of Kynureninase.

The symbols are the same as in Fig. 1. Regression line: Kynureninase $(\mu \mathrm{mol} / \mathrm{hr} / \mathrm{g})=(-0.015) \times($ Blood Glucose $(\mathrm{mg} / \mathrm{ml}))+(0.190)(r=-0.700, p<0.05)$.

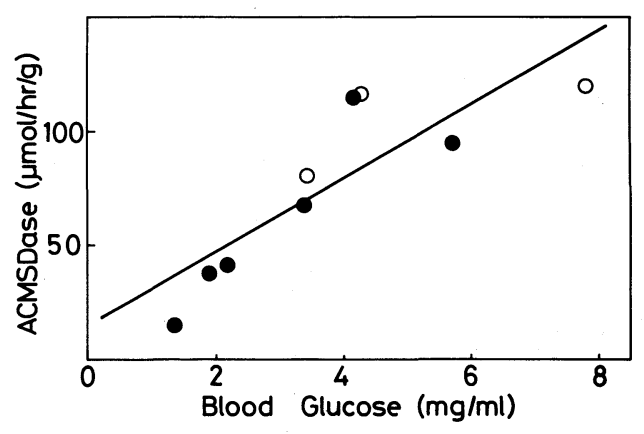

FIG. 4. Correlation between the Concentration of Blood Glucose and the Activity of ACMSDase.

The symbols are the same as in Fig. 1. Regression line: ACMSDase $\quad(\mu \mathrm{mol} / \mathrm{hr} / \mathrm{g})=(16.157) \times($ Blood Glucose $(\mathrm{mg} / \mathrm{ml}))+(15.200)(r=0.844, p<0.01)$.

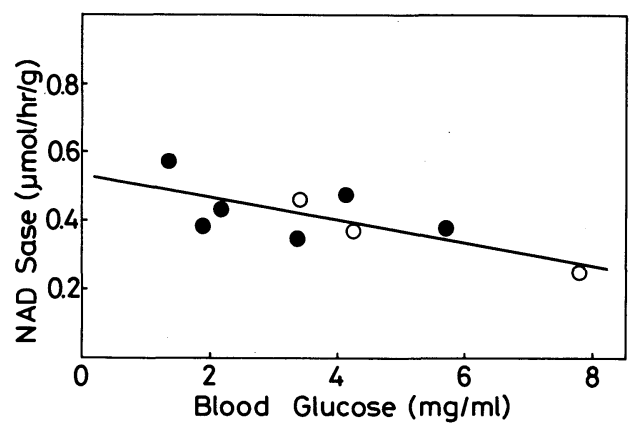

FIG. 5. Correlation between the Concentration of Blood Glucose and the Activity of NAD ${ }^{+}$Synthetase.

The symbols are the same as in Fig. 1. Regression line: NAD Sase $(\mu \mathrm{mol} / \mathrm{hr} / \mathrm{g})=(-0.033) \times($ Blood Glucose $(\mathrm{mg} / \mathrm{ml}))+(0.530)(r=-0.729, p<0.05)$. 


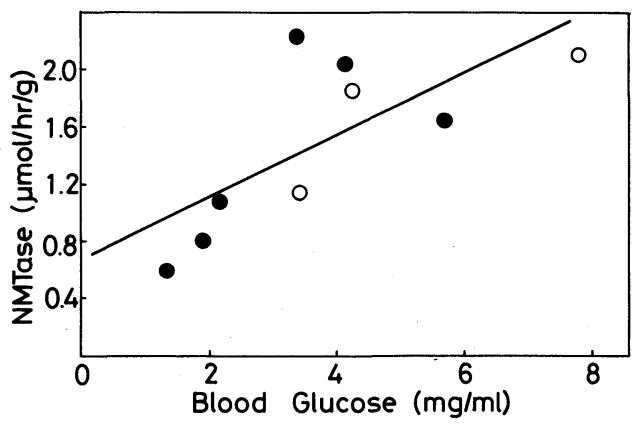

FIG. 6. Correlation between the Concentration of Blood Glucose and the Activity of Nicotinamide Methyltransferase.

The symbols are the same as in Fig. 1. Regression line: NMTase $(\mu \mathrm{mol} / \mathrm{hr} / \mathrm{g})=(0.216) \times($ Blood Glucose $(\mathrm{mg} /$ $\mathrm{ml}))+(0.673)(r=0.722, p<0.05)$.

activities of tryptophan oxygenase, kynureninase, aminocarboxymuconate-semialdehyde decarboxylase, $\mathrm{NAD}^{+}$synthetase, or nicotinamide methyltransferase, and the concentration of blood glucose. In all the above enzymes, this relation was significant at $p<0.05$. The activities of tryptophan oxygenase, aminocarboxymuconate-semialdehyde decarboxylase, and nicotinamide methyltransferase increased with increases in the concentration of blood glucose, while the activities of kynureninase and $\mathrm{NAD}^{+}$synthetase decreased with increases in the concentration of blood glucose.

\section{DISCUSSION}

Ikeda et $a .^{2)}$ reported that there was no significant change in the activity of kynureninase and 3-hydroxyanthranilic acid oxygenase in alloxan diabetic rats compared with normal rats. In this experiment, these enzyme activities and the activity of NMN adenylyltransferase were not changed by the injection of alloxan in the groups on the control and the nicotinamide diets. However, the activity of kynureninase was inversely related to the concentration of blood glucose. A marked increase in the activity of aminocarboxymuconate-semialdehyde decarboxylase, which is inversely related to the formation of quinolinic acid, was observed by the injection of alloxan in both diets, as reported by Mehler et al., ${ }^{1)}$ Ikeda et al. ${ }^{2)}$ and Sanada et $a l .{ }^{3)}$ The increase in the activity of aminocarboxymuconate-semialdehyde decarboxylase tended to be lower in the group of $\mathrm{N}-\mathrm{A}$ than in the group of $\mathrm{C}-\mathrm{A}$. It is noticeable that the activity of aminocarboxymuconate-semialdehyde decarboxylase was lower in the group of $\mathrm{N}-\mathrm{C}$ than in the group of $\mathrm{C}-\mathrm{C}$. Nicotinamide may inhibit the activity of aminocarboxymuconate-semialdehyde decarboxylase. In the control diet, the activity of kynurenine aminotransferase was increased about 4-fold by the injection of alloxan, and the increased activity of kynurenine aminotransferase in the alloxan diabetic rats was consistent with the reports of the increased urinary xanthurenic acid in diabetics following oral tryptophan administration by Kotake and Tani, ${ }^{4)}$ Rosen et al. ${ }^{5)}$ and McDaniel et al., ${ }^{14)}$ while on the nicotinamide diet, it was not increased by the injection. Partial prevention by nicotinamide in alloxan-induced diabetes could be attributed to the inhibition of increase in the activities of aminocarboxymuconate-semialdehyde decarboxylase and kynurenine aminotransferase. Although Mehler et al. ${ }^{1)}$ and Sanada et al. ${ }^{3)}$ reported that there was a marked reduction of urinary MNA in the alloxan diabetic rat, the activity of nicotinamide methyltransferase was increased by the injection of alloxan. This is attributed to the fact that the limiting factor of MNA formation is the level of nicotinamide, one of the substrates, rather than the concentration of nicotinamide methyltransferase. ${ }^{12)}$ McDaniel et al. ${ }^{14)}$ reported that the conversion of tryptophan to niacin decreased in alloxan diabetic rats, compared with normal rats. In this experiment, its conversion is considered to decrease in alloxan diabetic rat, from the results of the higher activities of aminocarboxymuconate-semialdehyde decarboxylase and kynurenine aminotransferase, and the lower activities of kynureninase and $\mathrm{NAD}^{+}$synthetase. Although the activity of tryptophan oxygenase was increased by the 
injection of alloxan, its increased activity has been reported not to contribute to the conversion of tryptophan to niacin. ${ }^{13)}$

In the groups receiving the alloxan injection, the values among rats were changeable. Accordingly, the correlation between the concentration of blood glucose and the activity of each enzyme was investigated. The activities of tryptophan oxygenase, aminocarboxymuconate-semialdehyde decarboxylase, and nicotinamide methyltransferase were in direct proportion to the concentration of blood glucose. On the other hand, the activity of kynureninase and $\mathrm{NAD}^{+}$synthetase were in reverse proportion. These changes of enzyme activities clearly show that the conversion ratio of tryptophan to niacin decreases with an increasing concentration of blood glucose.

It is known that streptozotocin-induced diabetes can be overcome when a large amount of nicotinamide is injected before the injection of streptozotocin, ${ }^{15)}$ but the prevention by nicotinamide treatment is low in alloxan-induced diabetes. ${ }^{16,17)}$ When a diet containing a large amount of nicotinamide was fed to rats, partial prevention by nicotinamide in alloxan treatment was observed; of six rats, the concentration of blood glucose of three rats were normal and the activity of kynurenine aminotransferase in the group of $\mathrm{N}-\mathrm{A}$ was not increased in comparison of the group of $\mathrm{N}-\mathrm{C}$. The concentration of blood glucose was higher in the group of $\mathrm{N}-\mathrm{C}$ than in the group of $\mathrm{C}-\mathrm{C}$; by administration of a large amount of nicotinamide, the concentration of blood glucose was increased. Its treatment may slightly disturb the metabolism of glucose as reported by Ishigami et al., ${ }^{18)}$ nevertheless nicotinamide partly prevents alloxan-induced diabetes.

\section{REFERENCES}

1) A. H. Mehler, E. G. McDaniel and J. M. Hundley, J. Biol. Chem., 232, 323 (1958).

2) M. Ikeda, H. Tsuji, S. Nakamura, A. Ichiyama, Y. Nishizuka and O. Hayaishi, J. Biol. Chem., 240, 1395 (1965).

3) H. Sanada, M. Miyazaki and T. Takahashi, J. Nutr. Sci. Vitaminol., 26, 449 (1980).

4) Y. Kotake and S. Tani, J. Biochem., 40, 295 (1953).

5) D. A. Rosen, G. D. Meangwyn-Davies, B. Becker, H. H. Stone and J. S. Freidenwald, Proc. Soc. Exp. Biol. Med., 88, 321 (1955).

6) K. Shibata, K. Murata, T. Hayakawa and K. Iwai, $J$. Nutr. Sci. Vitaminol., 31, 265 (1985).

7) W. E. Knox, A Yip and L. Reshef, "Methods in Enzymology," Vol. 17A, ed. by H. Tabor and C. W. Tabor, Academic Press, New York, 1970, p. 415.

8) F. Takeuchi, H. Otsuka and Y. Shibata, J. Biochem., 88, 987 (1980).

9) R. H. Decker, H. H. Kang, F. R. Leach and L. M. Henderson, J. Biol. Chem., 236, 3076 (1961).

10) M. C. Tobes and M. Mason, Biochem. Biophys. Res. Commun., 62, 390 (1975).

11) A. Ichiyama, S. Nakamura, H. Kawai, T. Honjo, Y. Nishizuka, O. Hayaishi and S. Senoh, J. Biol. Chem., 240, 740 (1965).

12) K. Shibata, Agric. Biol. Chem., 50, 1489 (1986).

13) K. Shibata, K. Tanaka and K. Murata, The Bulletin of Teikoku Gakuen, No. 9, 1 (1983).

14) E. G. McDaniel, J. M. Hundley and W. H. Sebrell, J. Nutr., 59, 407 (1956).

15) P. S. Schein, D. A. Cooney and M. L. Vernon, Cancer Res., 27, 2324 (1967).

16) W. Stauffacher, I. Burr, A. Gutzeit, D. Beaven, J. Veleminsky and A. E. Renold, Proc. Soc. Exp. Biol. Med., 133, 194 (1970).

17) P. Masiello and E. Bergamini, Experimentia, 33, 1246 (1977).

18) R. Ishigami, S. Shiotani, A. Yoshida, T. Kawata, H. Natori, Y. Akiyama, J. Omoto and H. Okata, Vitamins (Japan), 32, 232 (1965).

19) K. Wakabayashi, "Zikken Data no Seiri," (in Japanese), Baifukan, Tokyo, 1984, p. 44. 